\title{
Remote sensing of multiple cloud layer heights using multi-angular measurements
}

\author{
Kenneth Sinclair $^{1,2}$, Bastiaan van Diedenhoven ${ }^{2,3}$, Brian Cairns ${ }^{2}$, John Yorks ${ }^{4}$, Andrzej Wasilewski ${ }^{5}$, and \\ Matthew McGill ${ }^{4}$ \\ ${ }^{1}$ Department of Earth and Environmental Engineering, Columbia University, New York, NY 10025, USA \\ ${ }^{2}$ NASA/Goddard Institute for Space Studies, 2880 Broadway, New York, NY 10025, USA \\ ${ }^{3}$ Center for Climate Systems Research, Columbia University, New York, NY 10025, USA \\ ${ }^{4}$ NASA Goddard Space Flight Center, Greenbelt, MD 20771, USA \\ ${ }^{5}$ Trinnovim LLC, New York, NY, USA \\ Correspondence to: Kenneth Sinclair (kenneth.sinclair@columbia.edu)
}

Received: 3 January 2017 - Discussion started: 3 February 2017

Revised: 30 April 2017 - Accepted: 3 May 2017 - Published: 29 June 2017

\begin{abstract}
Cloud top height (CTH) affects the radiative properties of clouds. Improved CTH observations will allow for improved parameterizations in large-scale models and accurate information on $\mathrm{CTH}$ is also important when studying variations in freezing point and cloud microphysics. NASA's airborne Research Scanning Polarimeter (RSP) is able to measure cloud top height using a novel multi-angular contrast approach. For the determination of CTH, a set of consecutive nadir reflectances is selected and the cross correlations between this set and collocated sets at other viewing angles are calculated for a range of assumed cloud top heights, yielding a correlation profile. Under the assumption that cloud reflectances are isotropic, local peaks in the correlation profile indicate cloud layers. This technique can be applied to every RSP footprint and we demonstrate that detection of multiple peaks in the correlation profile allows retrieval of heights of multiple cloud layers within single RSP footprints. This paper provides an in-depth description of the architecture and performance of the RSP's CTH retrieval technique using data obtained during the Studies of Emissions and Atmospheric Composition, Clouds and Climate Coupling by Regional Surveys (SEAC ${ }^{4} \mathrm{RS}$ ) campaign. RSP-retrieved cloud heights are evaluated using collocated data from the Cloud Physics Lidar (CPL). The method's accuracy associated with the magnitude of correlation, optical thickness, cloud thickness and cloud height are explored. The technique is applied to measurements at a wavelength of 670 and $1880 \mathrm{~nm}$ and their combination. The $1880 \mathrm{~nm}$ band is
\end{abstract}

virtually insensitive to the lower troposphere due to strong water vapor absorption.

It is found that each band is well suitable for retrieving heights of cloud layers with optical thicknesses above about 0.1 and that RSP cloud layer height retrievals more accurately correspond to CPL cloud middle than cloud top. It is also found that the $1880 \mathrm{~nm}$ band yields the most accurate results for clouds at middle and high altitudes (4.0 to $17 \mathrm{~km}$ ), while the $670 \mathrm{~nm}$ band is most accurate at low and middle altitudes $(1.0-13.0 \mathrm{~km})$. The dual band performs best over the broadest range and is suitable for accurately retrieving cloud layer heights between 1.0 and $16.0 \mathrm{~km}$. Generally, the accuracy of the retrieved cloud top heights increases with increasing correlation value. Improved accuracy is achieved by using customized filtering techniques for each band with the most significant improvements occurring in the primary layer retrievals. RSP is able to measure a primary layer $\mathrm{CTH}$ with a median error of about $0.5 \mathrm{~km}$ when compared to CPL. For multilayered scenes, the second and third layer heights are determined median errors of about 1.5 and $2.0-2.5 \mathrm{~km}$, respectively.

\section{Introduction}

Clouds cover roughly two thirds of the globe (Mace et al., 2009) and act as an important regulator of the Earth's radiation budget (Boucher et al., 2013). Changes to cloud ver- 
tical structure (location of cloud top and base, number and thickness of layers) affect the radiative properties of clouds (Boucher et al., 2013) and can have significant effects on climate (Collins et al., 1994). In addition to global studies, detailed regional observations are crucial to improve our physical understanding of the relationships between cloud top height (CTH), environmental conditions and other cloud properties. Furthermore, accurate information on CTH is critical when studying vertical variations in freezing point and other cloud microphysical parameters such as particle effective radius and ice particle shape (Alexandrov et al., 2015, 2016; Lensky and Rosenfeld, 2006; Rosenfeld et al., 2008; van Diedenhoven et al., 2014, 2016). Additional observations of cloud top height will lead to a better understanding of its relationship to cloud thermodynamic phase, atmospheric dynamics, relative humidity and aerosol concentrations that is needed for improved sub-grid parameterizations in largescale models.

Wang and Rossow (1998) found that the three most important parameters linking clouds to the circulation of the Earth's atmosphere in general circulation models (GCMs) are the height of the top layer, the presence of multilayered clouds and the separation distance between layers in multilayered systems. Wang et al. (2000) found that multilayered clouds occur $42 \%$ of the time and are predominantly two-layered with an average separation of $2.2 \mathrm{~km}$. Multilayer clouds are challenging for radiometric instruments, affecting retrievals of many cloud properties, particularly CTH. Traditionally, most passive remote sensing instruments are limited to the retrieval of information from the uppermost cloud layer or column-integrated properties (Wang et al., 2000; Menzel et al., 2008; Fisher et al., 2016).

Passive methods capable of retrieving CTH that have been implemented use techniques including photogrammetry (Muller et al., 2002), oxygen A-band absorption (Wu, 1985; van Diedenhoven et al., 2007), $\mathrm{CO}_{2}$ slicing (Menzel et al., 1983), Rayleigh scattering of polarized reflectance at short wavelengths (Buriez et al., 1997; van Diedenhoven et al., 2013) and $11 \mu \mathrm{m}$ window brightness temperatures (Menzel et al., 2008). Cloud top pressure can be determined by using a ratio of two radiances in the oxygen $\mathrm{A}$ band, whereby one measured radiance covers the A band and windows on either side and the other is inside the oxygen absorption band. The Polarization and Directionality of the Earth's Reflectances (POLDER) instrument uses this technique (Buriez et al., 1997). POLDER also uses observations of polarized reflectance at $443 \mathrm{~nm}$, which is dominated by molecular scattering and related to the pressure of air above clouds (Buriez et al., 1997). Moderate Resolution Imaging Spectroradiometer (MODIS) instruments use a $\mathrm{CO}_{2}$ slicing technique that is based on $\mathrm{CO}_{2}$ being a uniformly mixed gas that becomes more opaque lower in the atmosphere due to $\mathrm{CO}_{2}$ absorption as the wavelength increases from 13.3 to $15 \mu \mathrm{m}$ (Menzel et al., 2008; Wind et al., 2010). Radiances obtained from within this range are therefore sensitive to different heights in the atmosphere. MODIS can also measure cloud top height using brightness temperature measurements in the $11 \mu \mathrm{m}$ atmospheric window under the assumption of clouds emitting as grey bodies and either the cloud being opaque or knowing it's optical thickness and the temperature of the lower layer. The Multi-angle Imaging SpectroRadiometer (MISR) (Marchand et al., 2007) uses photogrammetry which applies the concept of "parallax", or changes in the apparent position of a cloud with view angle, to calculate the height of the cloud above the surface. Cloud heights are identified using either an area-based or a feature-based matching algorithm. The multipoint matcher using means (M2) and multipoint matcher using medians (M3) are common methods (Muller et al., 2002). The methods determine a single altitude by matching pixels from multiple images that minimizes the difference and is below a predetermined threshold (Diner et al., 1999). Using MISR and MODIS, Naud et al. (2007) found that multilayered cloud scenes increase single-layered CTH retrieval errors. Multiple cloud layers were found to be detectable by looking at the discrepancy between MODIS and MISR CTHs. However, multilayered clouds went undetected when both MODIS and MISR detected the same layer. MISR tends to retrieve the layer of higher contrast, which is most often the lower, optically thicker layer (Naud et al., 2002).

Here, we present a novel multi-angular contrast approach to retrieve CTH that is applied to NASA's airborne Research Scanning Polarimeter (RSP). The approach uses photogrammetry and can be applied to every RSP footprint. We demonstrate the method's ability to retrieve heights of multiple cloud layers within single RSP footprints, using the multiple views available for each footprint. This paper provides an in-depth description and performance analysis of the RSP's CTH retrieval technique using data obtained during the Studies of Emissions and Atmospheric Composition, Clouds and Climate Coupling by Regional Surveys (SEAC ${ }^{4} \mathrm{RS}$; Toon et al., 2016) campaign. The retrieved cloud heights are evaluated using collocated data from the Cloud Physics Lidar (CPL; McGill et al., 2002). Given the strong variability in cloud top heights, the presence of multilayered cloud and the collocation of RSP and CPL, the SEAC ${ }^{4}$ RS campaign provides an exceptional dataset for evaluating the multi-angular contrast approach for cloud top height retrievals. Accurate RSP cloud top height measurements and the identification of multilayered clouds are important to provide context for the other RSP cloud products including particle effective radius, cloud top phase and ice crystals shape (Alexandrov et al., 2015, 2016; van Diedenhoven et al., 2016).

Section 2 provides details on the campaign and data that are used in addition to background information on RSP and CPL. Section 3 gives a description of the retrieval approach. Section 4 presents a full mission comparison with CPL and a performance analysis evaluating the strengths and weaknesses of the approach. This section is concluded with a final analysis using the most effective retrieval parameters. Section 5 concludes the analysis by reviewing the main results 
along with a discussion of tradeoffs between the capabilities and limitations of the technique.

\section{Measurements}

\subsection{RSP}

The RSP (Cairns et al., 1999) is an airborne prototype of the Aerosol Polarimetry Sensor (APS) that was on board the Glory satellite, which failed to reach orbit in March 2011. RSP makes polarimetric and total intensity measurements in nine spectral bands in the visible/near-infrared and shortwave infrared, scanning along the track of the aircraft over a maximum of 152 viewing angles spaced $0.8^{\circ}$ apart. The instantaneous field of view of the RSP is $14 \mathrm{mrad}$, resulting in a pixel size of about $280 \mathrm{~m}$ on the ground when flying at $20 \mathrm{~km}$, with the pixel size decreasing as cloud tops get closer to the aircraft altitude. RSP is able to sweep $\pm 60^{\circ}$ from nadir along the aircraft's track. However, when mounted on the ER-2 only 134 angles are usable ranging from $41^{\circ}$ forward to $79^{\circ}$ aft. When the aircraft orientation and velocity vector are aligned (i.e., no yaw), multiple scans will measure the same feature multiple times from a variety of angles, which can be aggregated into "virtual" scans consisting of the reflectance at the full range of viewing angles for a single footprint at the cloud top (Alexandrov et al., 2012). If the reflectance is not aggregated to the correct cloud top, then different angles observe different locations on the cloud.

RSP is able to measure aerosol, cloud and ground heights using a novel multi-angular contrast approach detailed in Sect. 3.1, which is a variation on the method described by Marchand et al. (2007). Here, cloud and some aerosol layer heights are calculated using three different sets of spectral bands: the 670 , the 1880 and a $670 / 1880 \mathrm{~nm}$ pair. The $1880 \mathrm{~nm}$ band is virtually insensitive to the lower troposphere due to strong water vapor absorption (Meyer et al., 2016) and has been shown to best sense optically thin higher-altitude clouds, while the visible $670 \mathrm{~nm}$ band is sensitive to the $\mathrm{CTH}$ of lower-level optically thicker clouds. The dual band configuration aims to make use of the strengths of each individual bands.

\subsection{CPL}

The CPL is a lidar system, built for use on the NASA ER-2 high-altitude aircraft, capable of profiling with $30 \mathrm{~m}$ vertical and $200 \mathrm{~m}$ horizontal resolution at 1064, 532 and $355 \mathrm{~nm}$ (McGill et al., 2002). CPL is pointed at $1-2^{\circ}$ from nadir, depending on aircraft attitude. The CPL and RSP instruments have similar fields of view and here CPL and RSP observations with the closest time stamps are compared. CPL measures vertical profiles of backscatter to height of signal attenuation (an optical thickness of about 3), providing cloud vertical structure, including cloud top height, depth and presence of multiple cloud layers. CPL determines CTH by using its fundamental measurement of a range-resolved profile of backscatter intensity. These profiles contain backscatter signals from a variety of entities including clouds, aerosol layers, regions of clear air and returns from the Earth's surface. CPL can also determine cloud phase by measuring the depolarization ratio of the $1064 \mathrm{~nm}$ output (Yorks et al., 2011). Here we use the CPL layer products including extinction, layer top height, layer bottom height and layer type (McGill et. al., 2002). Layers identified as aerosol and cloud layers are both included in the analysis since CPL tends to occasionally misclassify clouds as aerosols. Furthermore, RSP's algorithm is not restricted to cloud layers and is capable of inferring heights of elevated thick aerosol layers too.

\subsection{SEAC $^{4} \mathrm{RS}$ campaign}

The NASA-led SEAC ${ }^{4}$ RS campaign (Toon et al., 2016) was primarily based in Houston in 2013 and targeted the continental United States and the Gulf of Mexico. A multitude of remote sensing and in situ information was collected with the goals of enhancing our understanding of how natural and anthropogenic pollution affect atmospheric chemistry, composition and climate. The campaign collected information with a variety of instruments including polarimeters, spectrometers, lidar, radar as well as in situ probes. During this campaign, the RSP and CPL were mounted on NASA's ER2 high-altitude aircraft flying at a nominal altitude of 18 $20 \mathrm{~km}$. The CPL's nadir measurement is made within $1-2^{\circ}$ of RSP's, allowing cloud measurements to be directly compared.

Data used in this analysis were collected over eight flights during the SEAC ${ }^{4} \mathrm{RS}$ experiment including 21 August and $2,4,11,13,16,18$ and 22 September 2013. Special focus is given to a leg of the ER-2 aircraft flight path on 16 September 2013 starting at 16.6 UTC, when a multilayered cloud was encountered.

\section{Retrieval methodology}

\subsection{CTH retrieval approach}

RSP's multi-angular contrast approach to retrieve CTH uses the concept of parallax as depicted in Fig. 1. First, the variation of nadir reflectances over a given number of sequential footprints is determined. For this study, we use sets of 17 measurements consisting of one at the footprint for which the CTH is being inferred plus 8 measurements before and after (Fig. 1a, blue box). The cumulative cross correlation between this set of nadir measurements and measurements at other viewing angles is determined for data that are aggregated to a range of assumed cloud top heights placed at $100 \mathrm{~m}$ vertical increments ranging from 0 to $20 \mathrm{~km}$ (Fig. 1a, red and purple boxes). Given the statistics of the results presented later, the $100 \mathrm{~m}$ increment was deemed sufficiently small. Differing footprint sizes resulting from viewing an- 


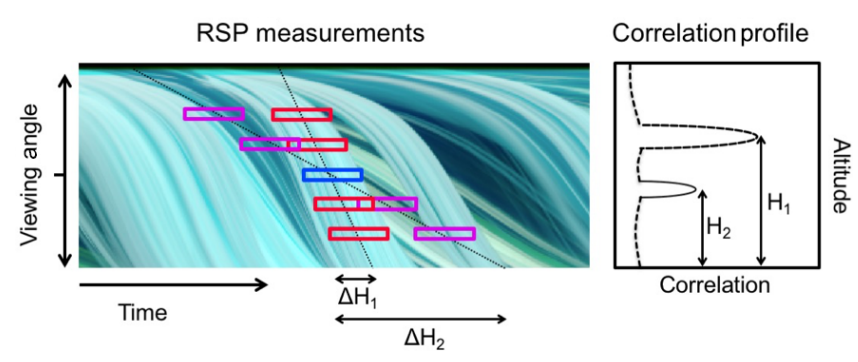

Figure 1. Illustration of the CTH retrieval approach with (a) RSP intensity measurements shown with reference nadir reflectances (blue box) along with two sets of reflectances assuming two different cloud top heights (red and purple boxes) and (b) the corresponding correlation profile.

gle geometry are not considered to affect correlation profile results. For each nadir footprint obtained at time $t$, the normalized cumulative cross correlation $\rho(t, h)$ for aggregation height $h$ is calculated as

$$
\begin{aligned}
& \rho(t, h)= \\
& \frac{1}{N_{\theta}} \sum_{i=1}^{N_{\theta}} \frac{1}{N_{\mathrm{R}}} \sum_{j=1}^{N_{\mathrm{R}}} \frac{\left[R_{0, j}-\overline{R_{0}}\right]\left[R_{j}\left(\theta_{i}, h\right)-\overline{R\left(\theta_{i}, h\right)}\right]}{\sigma_{0} \sigma_{i}},
\end{aligned}
$$

where $R_{0}$ is the reference set of $N_{\mathrm{R}}$ nadir reflectances (referred to as nadir template hereafter), and $R\left(\theta_{i}, h\right)$ is a set of $N_{\mathrm{R}}$ reflectances measured at angle $\theta_{i}$ when aggregated at height $h$. As discussed above, here we take $N_{\mathrm{R}}=17$. Mean values of the reflectance $R_{0}$ and $R\left(\theta_{i}, h\right)$ are given by $\overline{R_{0}}$ and $\overline{R\left(\theta_{i}, h\right)}$, respectively, while the standard deviations of the reflectance are given by $\sigma_{0}$ and $\sigma_{i}$, respectively. $N_{\theta}$ is the total number of angles included, which is 134 for RSP mounted on the ER-2, as discussed above. Note that, for clarity, we omitted dependencies of all quantities on time $t$ in Eq. (1).

Computing the cross correlation for all aggregation heights at a single footprint results in a correlation profile as illustrated in Fig. 1b. Since the variation over sequential footprints is likely to be similar at all viewing angles, the cloud top height that leads to the highest correlation with the nadir reference set is taken to be the primary retrieved cloud layer height (Fig. 1b). Multiple peaks in the correlation profile can be indicative of multiple cloud layers and in some cases correspond to up to three cloud layers when valid second and third peaks are identified. Note that in most cases multiple peaks result from the RSP observing cloud layers beneath overcast, optically thin upper layers. This method is applied to all RSP footprints in each flight leg, creating a correlation map as depicted in Fig. 2.

To find peaks in correlation profiles that correspond to cloud layer heights, a boxcar smoothing function is first used to reduce noise; in this case the boxcar function is five bins wide and each bin has a $100 \mathrm{~m}$ height corresponding to the vertical increments used in constructing the correlation map. The first derivative of the smoothed data is taken from which
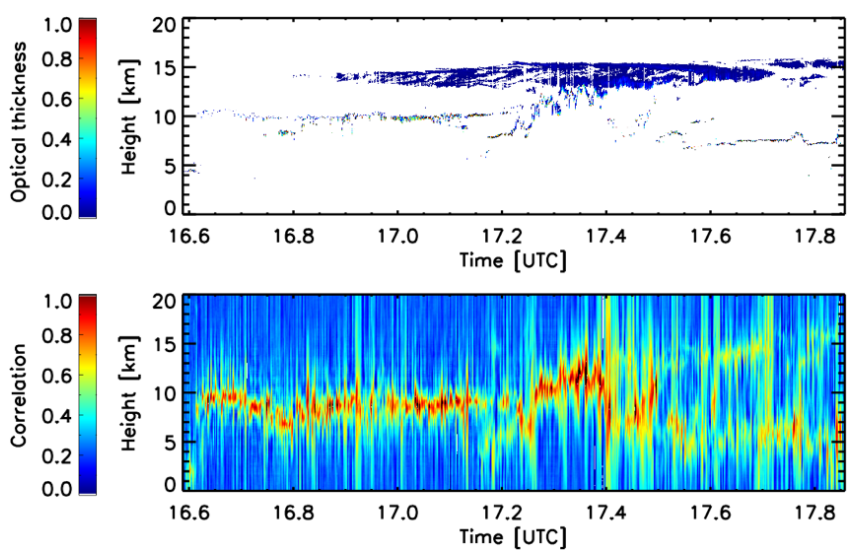

Figure 2. CPL optical thickness (top) and corresponding RSP correlation map (bottom) for 16 September 2013 from 16.6 to 17.85 UTC.

local maxima are taken. The largest local maximum corresponds to the primary layer height, while two subsequent largest local maxima are saved and may be used to identify multiple layers in the scene. This approach is applied to RSP measurements at 670 and $1880 \mathrm{~nm}$, the dual band approach first averages the correlation maps of each individual band before applying the smoothing function and retrieving the maxima. This yields three separate $\mathrm{CTH}$ products as evaluated in Sect. 4.

\subsection{Comparison with CPL}

Performance of the method is evaluated using CTHs retrieved by CPL. CPL data provide layer top height, layer bottom height and layer type for layers down to the level where the lidar attenuates, which is at an optical depth of about 3. Figure 3 details three cases showing CPL-retrieved cloud layers (grey) along with corresponding RSP correlation profiles for the $1880 \mathrm{~nm}$ channel. The RSP correlation profiles are taken from the same flight leg shown in Fig. 2. RSP cloud layers found using the method described in the above section are shown as blue stars in each of the plots.

\section{Results}

This section provides a performance analysis of the method with the goal of identifying strengths and weaknesses. Section 4.1 presents an analysis of the RSP technique applied to the SEAC ${ }^{4} \mathrm{RS}$ mission to quantitatively assess the method's ability to sense cloud layer heights. Section 4.2 compares the number of cloud layers detected by RSP and CPL. Section 4.3 analyzes aspects of the nadir template, including how its width and the variation of intensity within the template affect the accuracy of the method. Section 4.4 investigates how the magnitude of each layer's peak correlation is related to the accuracy of the retrieved CTH. Section 4.5 explores 

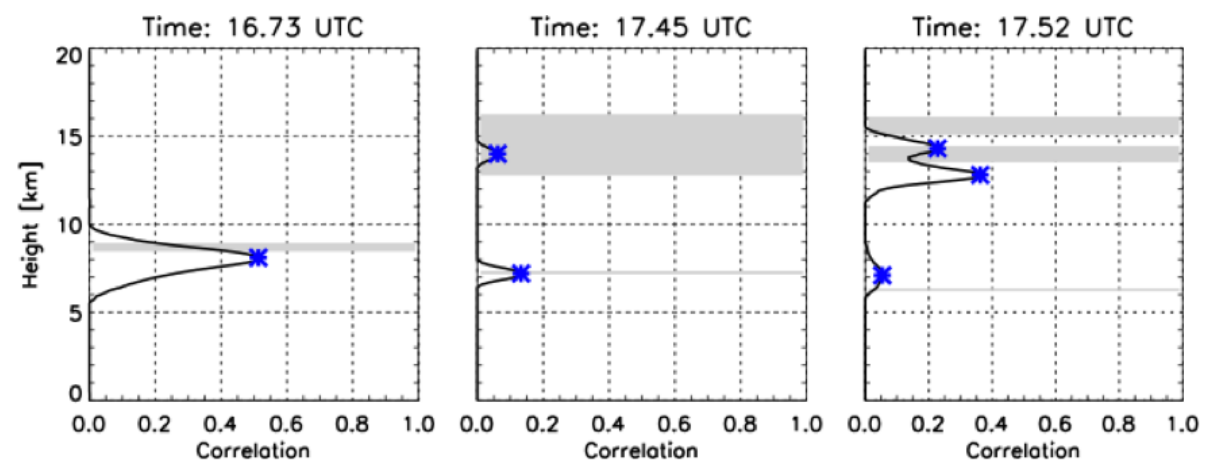

Figure 3. (a) A single-layer RSP correlation profile with the detected layer's height shown as a blue star and the CPL-detected cloud boundaries shown in light grey. (b) Same as panel (a) but detailing a two-layer cloud profile. (c) Same as panel (a) but detailing a three-layer cloud profile. Data were obtained on 16 September 2013.

how cloud optical thickness (COT) affects the accuracy of the method, giving special focus to optically thin clouds. Section 4.6 examines whether the RSP height retrieval better corresponds to CPL-retrieved cloud top or cloud middle and how this varies with altitude. Section 4.7 shows how the errors and biases of the first, second and third peaks vary with height. Lastly, Sect. 4.8 presents a summary of the comparison to CPL using an optimized set of retrieval parameters.

\subsection{RSP and CPL CTH comparison}

A summary of a baseline comparison between RSP and CPL, including the number of cases, median and mean differences, standard deviation and correlation coefficient, is given in Table 1 . The comparison uses minimal filtering, namely only considering (a) RSP correlation peaks aggregated between 1.0 and $17.5 \mathrm{~km}$ in order to avoid interference by the surface or the aircraft; (b) peaks with a minimum correlation value of 0.1 ; and (c) second and third correlation peaks with at least 0.5 times the primary peak correlation value. All retrieved RSP layers are compared to the top of the closest CPL layer. The comparison uses data collected over eight flights of the SEAC ${ }^{4} \mathrm{RS}$ campaign.

Results for each of the wavelength bands show a generally good agreement with the CPL observed heights. As seen in Table 1, the $1880 \mathrm{~nm}$ band's primary peak gives the best agreement with CPL with a $0.58 \mathrm{~km}$ median error. The dual band gives similar results $(0.61 \mathrm{~km})$ along with the largest number of valid data points (121679). The median error of the result using the $670 \mathrm{~nm}$ band is substantially larger at $0.74 \mathrm{~km}$ with 112911 valid data points. All bands yield strong correlation coefficients for primary layer heights and reasonable values for secondary heights. Third-layer metrics are notably degraded for all bands. The dual band consistently yields the highest number of valid comparisons with a performance similar to that of the $1880 \mathrm{~nm}$ band.

Figures 4-6 show direct comparisons of RSP-retrieved CTH for the first, second and third correlation peaks with the corresponding CPL layer top heights for the $1880 \mathrm{~nm}$,
Table 1. Summary of baseline comparison.

\begin{tabular}{llrrr}
\hline & & $\begin{array}{r}1880 \mathrm{~nm} \\
\text { band }\end{array}$ & $\begin{array}{r}670 \mathrm{~nm} \\
\text { band }\end{array}$ & $\begin{array}{r}\text { Dual } \\
\text { band }\end{array}$ \\
\hline First & Median error $(\mathrm{km})$ & 0.58 & 0.74 & 0.61 \\
& Mean error $(\mathrm{km})$ & 1.06 & 1.68 & 1.22 \\
& Np & 115783 & 112911 & 121679 \\
& SD & 1.90 & 2.67 & 2.14 \\
& Corr. coeff. & 0.87 & 0.81 & 0.87 \\
\hline \multirow{2}{*}{ Second } & Median error $(\mathrm{km})$ & 1.26 & 1.69 & 1.30 \\
& Mean error $(\mathrm{km})$ & 1.92 & 2.60 & 2.28 \\
& Np & 48883 & 51812 & 61961 \\
& SD & 2.79 & 3.29 & 3.25 \\
& Corr. coeff. & 0.71 & 0.66 & 0.68 \\
\hline \multirow{2}{*}{ Third } & Median error $(\mathrm{km})$ & 2.03 & 2.50 & 2.10 \\
& Mean error $(\mathrm{km})$ & 2.67 & 3.25 & 2.92 \\
& Np & 28493 & 32766 & 37577 \\
& SD & 3.58 & 3.77 & 3.70 \\
& Corr. coeff. & 0.58 & 0.55 & 0.58 \\
\hline
\end{tabular}

$670 \mathrm{~nm}$ and dual band results, respectively. Figure $4 \mathrm{a}$ shows that the primary layer heights retrieved with RSP's $1880 \mathrm{~nm}$ band correlate well with the corresponding CPL heights. There is a cluster of points where the RSP senses cloud layers at a high altitude while the CPL sees low-lying layers, with a difference of about $10 \mathrm{~km}$. This mismatch occurs primarily when the CPL is seeing through small spaces in a cloud, which are too small for the RSP to see through or near cloud edges. CPL has classified this group of points primarily as low-lying aerosol layers. Note that the $1880 \mathrm{~nm}$ band is located at a strong water vapor absorption band and not able to see deep into the atmosphere, particularly for the moist atmospheres observed during SEAC4RS, but is able to sense some high cirrus down to optical depths of $\sim 0.01$. The RSP is capable of observing optically thin aerosol layers. The error distribution (Fig. 4d, left bottom) shows a symmetric narrow peak centered slightly off-zero. The full width at half maxi- 
(a)
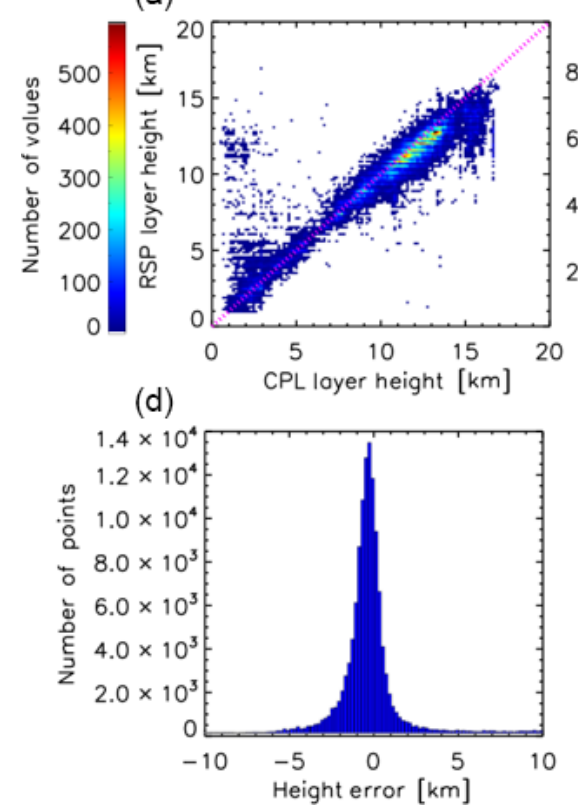

(b)

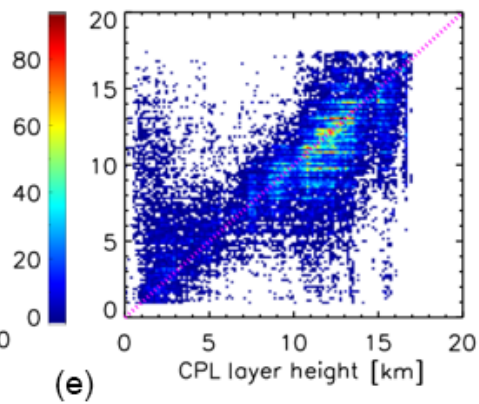

(e)

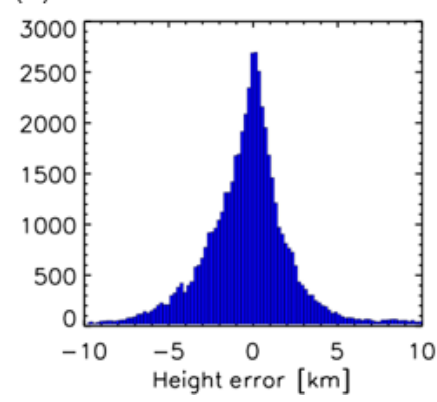

(c)

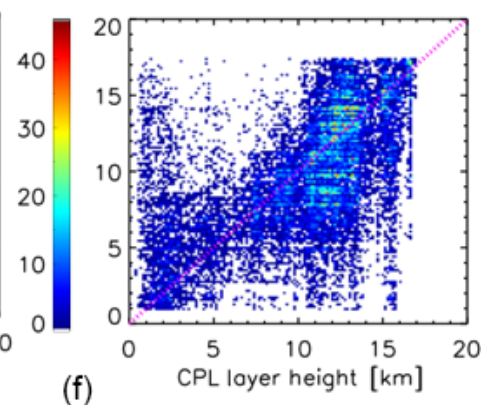

(f)

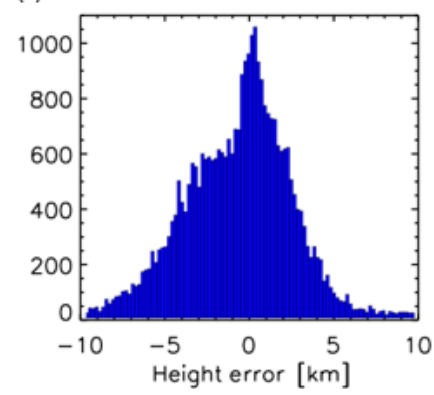

Figure 4. Comparison of CTH retrieved using the RSP $1880 \mathrm{~nm}$ band and CPL for the primary peak (top left), second peak (top middle) and third peak (top right) with their associated error distributions immediately below each scatterplot.

mum (FWHM) of the distribution is about $1.8 \mathrm{~km}$. The comparison for the CTH associated with the second correlation peak (Fig. 4b) has a similar shape but is more dispersed than the primary peak. This is apparent in the error distribution which is symmetrical, with little bias, but has a broader distribution than that associated with the primary layer heights, with a FWHM of $3.4 \mathrm{~km}$. The third peak (Fig. 4c) has a very similar spatial pattern as the second peak, but its error distribution (Fig. 4f) is no longer centered on zero bias, is more asymmetric and has a large FWHM of $7.5 \mathrm{~km}$.

Similarly to Fig. 4, Fig. 5 shows the comparison of the results using the $670 \mathrm{~nm}$ band with the CPL layer top heights. Again, the primary layer heights (Fig. 5a) agree well with the corresponding CPL heights, although there are a number of cases where the CPL senses high-altitude clouds while the RSP's $670 \mathrm{~nm}$ band detects low-lying features. This occurs when the CPL attenuates at a high altitude, but the RSP senses a strong low-lying feature. The higher feature may be distinguished in the $670 \mathrm{~nm}$ band's second or third layer heights. The corresponding error distribution (Fig. 5d) shows a centered, narrow and symmetric distribution with a FWHM of $2.0 \mathrm{~km}$, which is slightly broader than seen for the $1880 \mathrm{~nm}$ results (Fig. 4). However, there is a negative tail in the distribution resulting from the cases where RSP detects low-lying features while CPL detects higher clouds. The CTH comparison for the second correlation peak (Fig. 5b) shows good agreement between RSP and CPL CTHs, although the RSP senses many more low-lying features and because of this the error distribution (Fig. 5e) is asymmetric, with a negative offset from center, and has a relatively large FWHM of $3.2 \mathrm{~km}$.
The third peak (Fig. 5c) gives similar results to those found for the second peak, but the error distribution (Fig. 5f) has an even more pronounced asymmetry along with a very broad FWHM of $7.0 \mathrm{~km}$.

Figure 6 shows the comparison of RSP's dual band results to the closest CPL layer top heights. For the primary peak (Fig. 6a), good agreement is seen with points clustered along the $1: 1$ line along with two sets of outliers where the RSP senses high-altitude layers while the CPL senses low layers and vice versa. The error distribution (Fig. 6d) shows a narrow peak nearly centered around zero and is symmetric. The FWHM of the distribution is $1.3 \mathrm{~km}$. Again, the second and third peak comparisons are more dispersed, asymmetric and broader than the $1880 \mathrm{~nm}$ band results with FWHM values of 2.1 and $6.2 \mathrm{~km}$, respectively. The dual band is included in our analysis with the aim of combining the strength of the 1880 band to sense high thin cirrus with the capability of the $670 \mathrm{~nm}$ band to retrieve the heights of lower layers. Comparing Fig. 6 to Figs. 4 and 5 shows that indeed the strengths of the two channels are well combined. However, the biases of the 1880 and $670 \mathrm{~nm}$ towards high and low layers, respectively, as compared to the CPL are also apparent in the dual band results.

\subsection{Number of cloud layers}

The frequencies of scenes for which the first, second and third layers are detected by the RSP's $1880 \mathrm{~nm}, 670 \mathrm{~nm}$ and dual bands are given in Table 2 along with the corresponding percentages of layers that CPL senses in the same cases. 
(a)

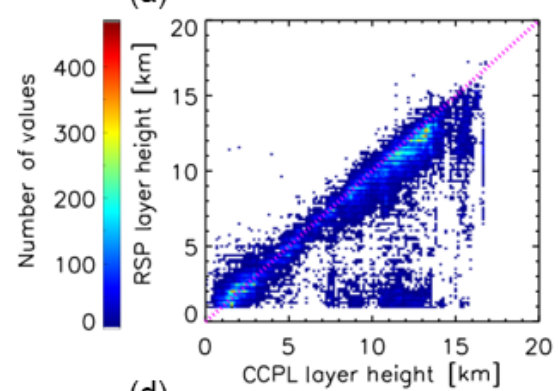

(d)

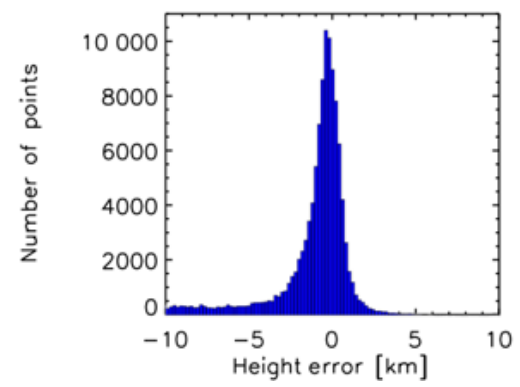

(b)

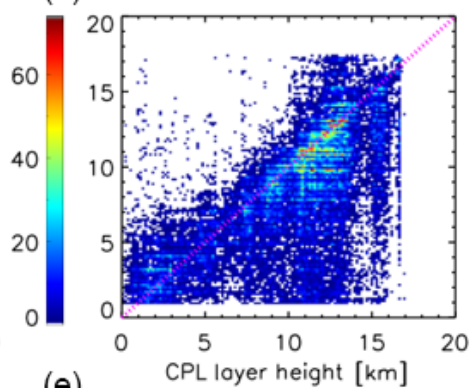

(e)

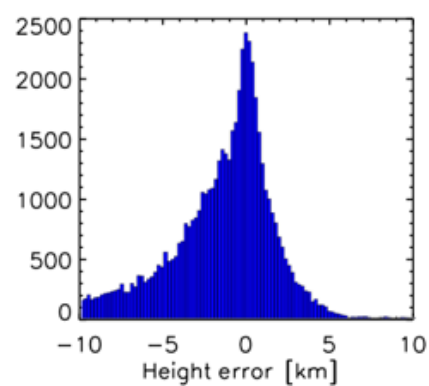

(c)

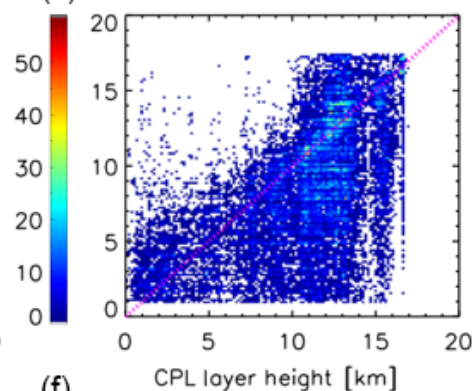

(f)

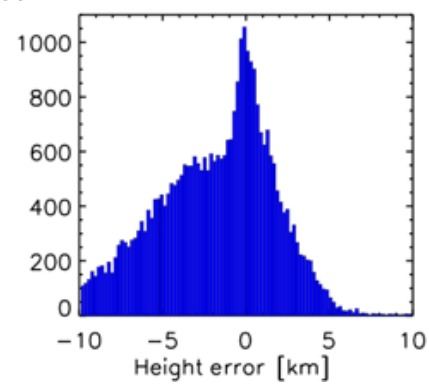

Figure 5. Same as Fig. 4 but for the $670 \mathrm{~nm}$ band results.

(a)
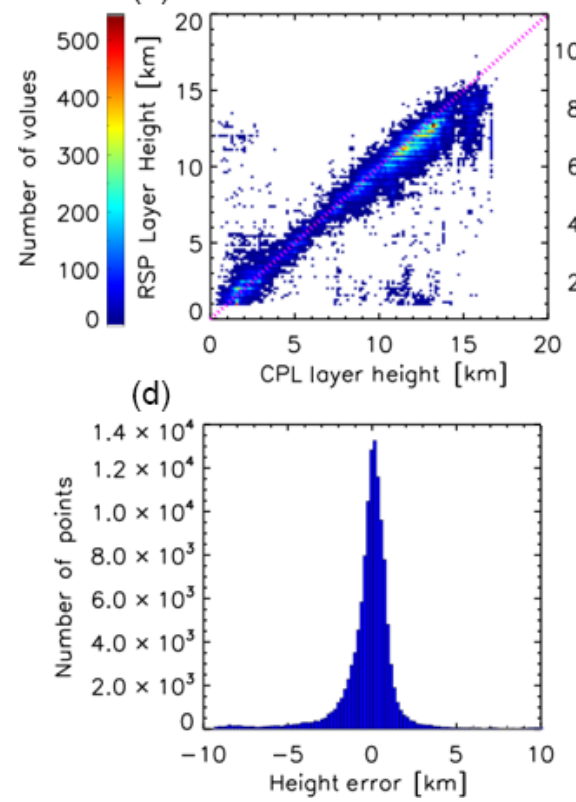

(b)
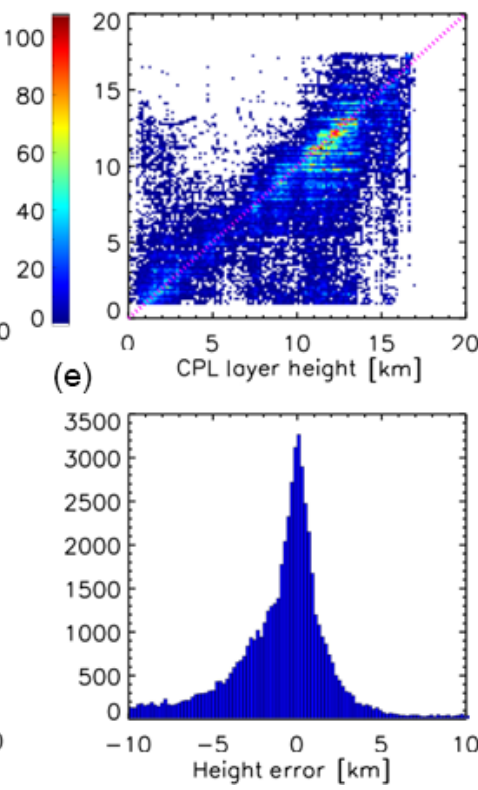

(c)

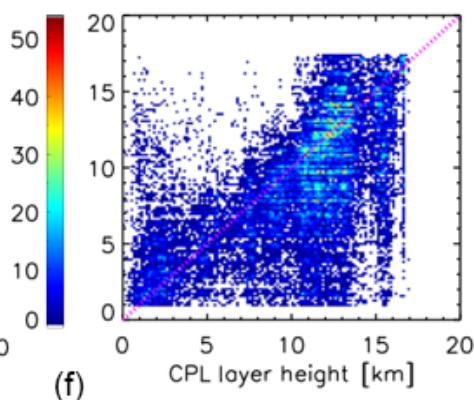

(f)

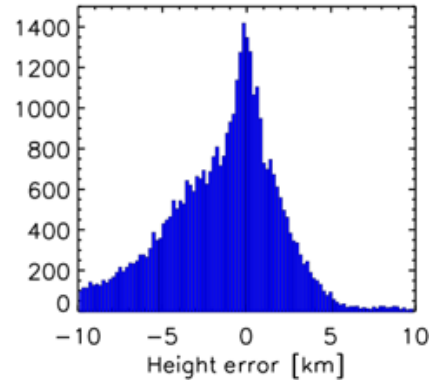

Figure 6. Same as Fig. 4 but for the dual band results.

For example, for the $1880 \mathrm{~nm}$ band, RSP observes a single cloud layer $68 \%$ of the time, and for these scenes the CPL sees a single layer $51 \%$ of the time, while detecting multiple layers for $47 \%$ of these cases. For only $1 \%$ of these cases does CPL not detect any layers. Generally, cases with multiple cloud layers are seen by RSP at a rate of about 30-40\% of the time, with about double the probability of detecting two-layer scenes than three-layer ones. For these multilay- ered cases, CPL generally detects multiple layers more often than in the cases where only a single layer is detected by RSP. However, still $40-44 \%$ of the time only a single layer is detected by CPL while RSP senses multiple layers, and when RSP detects a single layer then CPL detects multiple layers $42-47 \%$ of the time. The reason for this is likely the different methods involved in detecting multiple layers. CPL can observe vertical gaps within clouds but cannot see through 
(a)

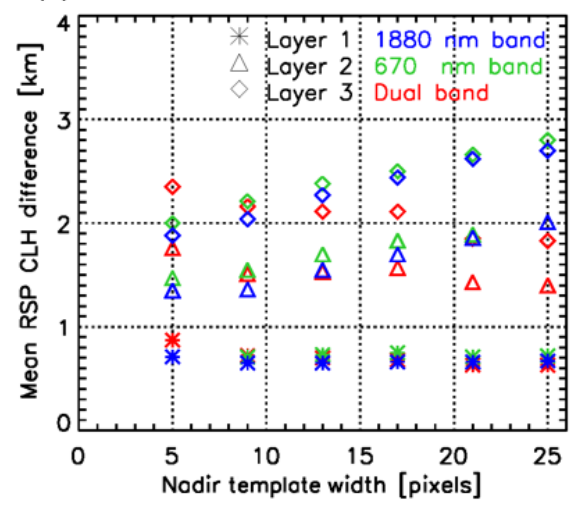

(b)

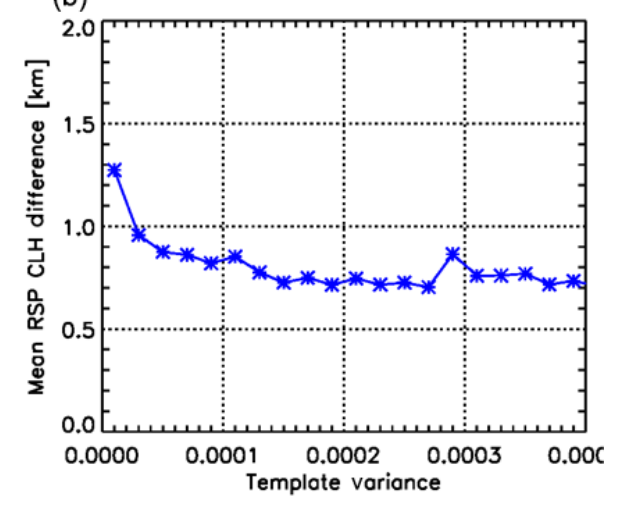

Figure 7. (a) RSP CTH error and nadir template width for the $1880 \mathrm{~nm}$ band (blue), $670 \mathrm{~nm}$ band (green) and the dual band (red). The first, second and third layers are shown as stars, triangles and diamonds, respectively. (b) Absolute CTH difference and template variance.

Table 2. The $1880 \mathrm{~nm}$ band RSP cloud layer percentages compared with CPL.

\begin{tabular}{|c|c|c|c|c|c|c|c|c|}
\hline & \multirow{2}{*}{$\begin{array}{l}\text { RSP } \\
\text { scenes }\end{array}$} & \multirow[t]{2}{*}{ Percentage } & \multicolumn{6}{|c|}{ Corresponding CPL layers } \\
\hline & & & 0 & 1 & 2 & 3 & 4 & 5 \\
\hline \multirow{3}{*}{$\begin{array}{l}1880 \mathrm{~nm} \\
\text { band }\end{array}$} & One-layer & 68 & 1 & 51 & 29 & 13 & 4 & 1 \\
\hline & Two-layer & 21 & 0 & 42 & 32 & 17 & 2 & 1 \\
\hline & Three-layer & 11 & 0 & 41 & 33 & 17 & 1 & 0 \\
\hline \multirow{3}{*}{$\begin{array}{l}670 \mathrm{~nm} \\
\text { band }\end{array}$} & One-layer & 66 & 1 & 52 & 28 & 12 & 4 & 1 \\
\hline & Two-layer & 21 & 0 & 44 & 32 & 15 & 2 & 1 \\
\hline & Three-layer & 13 & 0 & 42 & 31 & 16 & 1 & 0 \\
\hline \multirow{3}{*}{$\begin{array}{l}\text { Dual } \\
\text { band }\end{array}$} & One-layer & 60 & 1 & 57 & 27 & 10 & 4 & 1 \\
\hline & Two-layer & 25 & 0 & 43 & 33 & 16 & 2 & 1 \\
\hline & Three-layer & 15 & 0 & 40 & 33 & 17 & 2 & 1 \\
\hline
\end{tabular}

thick clouds, while RSP can see below thick clouds because it is viewing them from the side but cannot see gaps within a single cloud layer. Overall, a similar performance is seen for all band configurations, although RSP results from the dual band agree somewhat better with the number of layers detected by CPL than results for the two single bands.

\subsection{Nadir template attributes}

Variation in intensity within the nadir template $\left(R_{0}\right)$ and the template width $\left(N_{\mathrm{R}}\right)$ is an important aspect possibly affecting the correlation profile for a given pixel (Eq. 1). Figure 7a shows mean absolute error of each band as a function of the template pixel width $N_{\mathrm{R}}$. An increase in error can be seen for each band when the template width is less than 9 pixels. The $1880 \mathrm{~nm}$ band's error remains relatively constant for templates of width 9 or more, but the dual band configuration experiences a slight decrease in error with increasing template width. For second and third layers, both the $670 \mathrm{~nm}$ band and $1880 \mathrm{~nm}$ bands experience increases in error with increasing template width. The dual band configuration shows an overall reduction of error with increasing template width. For the analysis in this paper the template width is chosen to be 17. Based on Fig. 7a results are not expected to be substantially different when other template width are chosen. For a template width of 17 , Fig. $7 \mathrm{~b}$ shows how the variance of the $1880 \mathrm{~nm}$ band signal in the template is related to the accuracy of the retrieval for the primary layer height. This shows the mean absolute error of the primary layers height for the $1880 \mathrm{~nm}$ band. It can be seen that there is a general decrease in error associated with increasing template variance, out to about 0.00012 in variance where the reduction in error levels off. A noticeable increase in error can be observed for the lowest value of variance where the error increases by about $300 \mathrm{~m}$ compared to the adjacent value.

\subsection{Correlation value}

It is expected that the correlation strength of a given peak as calculated by Eq. (1) is related to the accuracy of the retrieved height. The effects of correlation value on the overall accuracy of the approach is investigated here. All RSP-retrieved CTH's between 1.0 and $17.5 \mathrm{~km}$ are considered. For layer CTHs detected using primary, second and third correlation peaks, Fig. 8a shows the accuracy for 0.05 -wide bins of correlation values. Figure $8 \mathrm{~b}$ shows the number of points that are included in each of the analyses.

Overall, it can be seen that lower correlation values result in less accurate CTH retrievals and that generally accuracy increases for all layers and bands as the correlation increases. The primary layer retrievals for all three bands increase in accuracy relatively quickly up to a correlation of about 0.45 beyond which there is little improvement in accuracy. For all bands, the second layer errors have a somewhat linear improvement in accuracy all the way up to a correlation value of 0.95 . The third layers also show a general improvement as correlation increases, although the small number of points results in a noisy pattern. From this, it is apparent that the correlation value can be used as an indicator of retrieval uncer- 
(a)

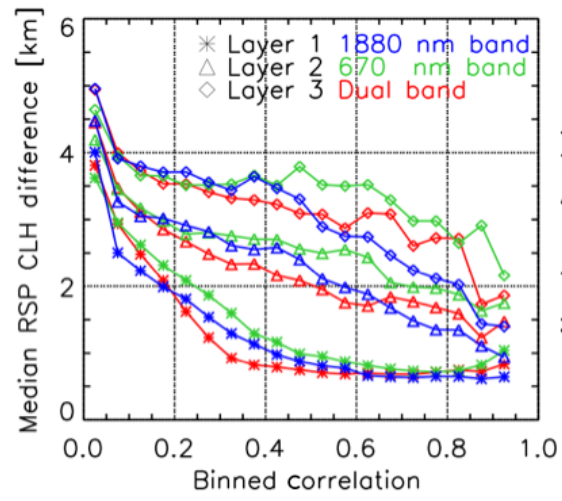

(b)

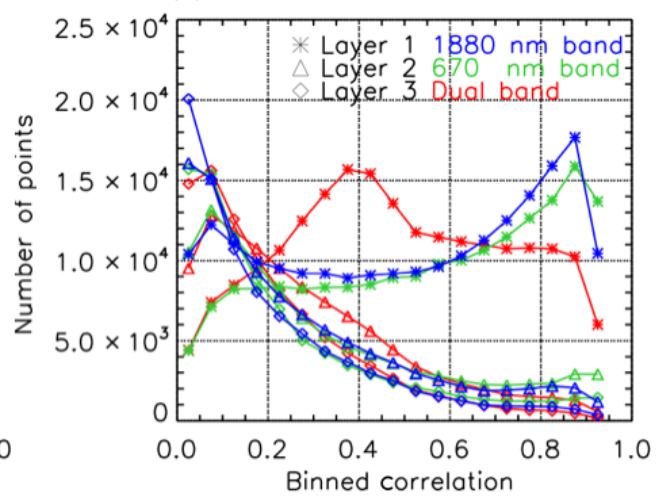

Figure 8. RSP CTH error (a) and number of samples (b) versus the minimum correlation for the $1880 \mathrm{~nm}$ band (blue), $670 \mathrm{~nm}$ band (green) and the dual band (red). The first, second and third layers are shown as stars, triangles and diamonds, respectively.

tainty. Furthermore, filtering the results using a unique minimum correlation value for each of the peaks would improve the general level of accuracy, although at the cost of reducing the overall number of retrievals.

\subsection{Cloud optical thickness}

Here we investigate how the method performs for varying COTs. Passive sensors are typically less sensitive to optically thin clouds, so it is important to know the accuracy of the RSP's ability to retrieve heights of clouds with low optical thicknesses. The CPL is capable of routinely sensing optically thin clouds and is able to accurately sense multilayered cloud scenes up to a total optical thickness of about 3. However, lidars are unable to sense cloud base of optically thick clouds or any clouds underneath. All of the comparisons start by using RSP-derived cloud heights; even as the layer optical thicknesses decrease, comparisons are only done when the RSP senses a layer, and there are likely instances not reflected in this assessment when CPL senses a thin layer that the RSP does not sense. For this part of the investigation, the baseline filtering described in Sect. 4.1 is used. Figure 9a shows the relation between the CPL optical thickness and the RSP cloud height error for all layers with calculated optical thicknesses. All bins are 0.25 wide except the last bin, which represents layers with optical thicknesses greater than 3.0. For the first layer, each of the bands' errors remain relatively constant throughout the range of COTs even for layers with an optical thickness below 0.1. If the RSP detects a layer, even of low optical thickness, it is consistent in its ability to determine the layer's height. There are many cases where CPL senses two or more layers and the mode separation difference is only $1 \mathrm{~km}$, so it is possible that more than one CPL layer can be contributing to RSP's retrieval. The errors have a slight, gradual increase with increasing optical thickness for the second and third layer. For clouds with optical thickness between 2.75 and 3.0, the difference between CPL and RSP heights is larger than for thinner clouds for all bands and layers. This increased difference between CPL and RSP cloud heights near the saturation optical depth of the CPL may indicate that RSP detects layers below the saturation level of CPL. Interestingly, the difference between CPL and RSP heights is smaller again for CPL optical thicknesses above 3. In all cases, the number of points decreases exponentially up to an optical thickness of about 2.75 when more optically thick layers are observed, as seen in the right panel of Fig. 9.

\subsection{Cloud top versus cloud middle}

Passive sensors detect photons that have been scattered from a range of depths within a cloud's diffuse boundary. In order to investigate to which depths within the cloud layers the retrieved layer heights pertain, we present here a comparison of the RSP cloud layer heights using the $1880 \mathrm{~nm}, 670 \mathrm{~nm}$ and dual bands with the CPL's cloud top and cloud middle heights. This part of the analysis only considers clouds where the CPL can sense both a top and bottom and is therefore limited to more tenuous clouds such that the CPL has not completely attenuated. Table 3 summarizes findings from the whole mission analysis.

In all cases of mean and median error the RSP layer height corresponds more accurately with CPL cloud middle height. The median error for the primary peak of all bands corresponds to CPL cloud middle 160-200 m (about 26\%) more accurately than cloud top. The improvement is less pronounced for the second and third layers comparison for all bands, with improvements varying between 70 and 170 and 50 and $150 \mathrm{~m}$, respectively. Similar correlation coefficients are obtained as with the comparison to CPL cloud top (Table 1). The general observation that RSP cloud layer heights correspond to a height somewhere within the cloud layers accounts for at least part of the biases seen in Figs. 4-6. 
(a)

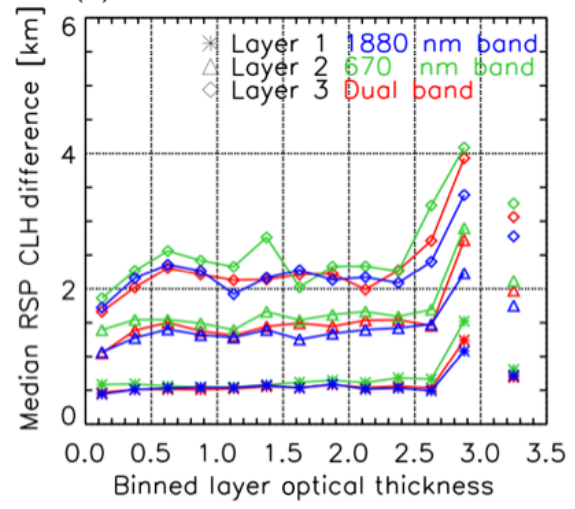

(b)

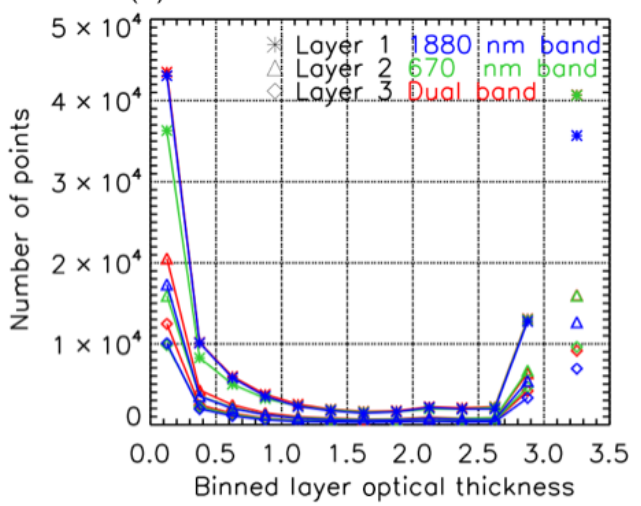

Figure 9. RSP CTH error (a) and number of samples (b) versus CPL cloud optical thickness for the $1880 \mathrm{~nm}$ band (blue), $670 \mathrm{~nm}$ band (green) and the dual band (red). The first, second and third layers are shown as stars, triangles and diamonds, respectively.

Table 3. Summary of cloud top and cloud middle comparison.

\begin{tabular}{llrr|rr|rr}
\hline & & \multicolumn{2}{c}{$1880 \mathrm{~nm}$ band } & \multicolumn{2}{c|}{$670 \mathrm{~nm}$ band } & \multicolumn{2}{c}{ Dual band } \\
\cline { 3 - 7 } & & $\begin{array}{r}\text { CPL cloud } \\
\text { top }\end{array}$ & $\begin{array}{r}\text { CPL cloud } \\
\text { middle }\end{array}$ & $\begin{array}{r}\text { CPL cloud } \\
\text { top }\end{array}$ & $\begin{array}{r}\text { CPL cloud } \\
\text { middle }\end{array}$ & $\begin{array}{r}\text { CPL cloud } \\
\text { top }\end{array}$ & $\begin{array}{r}\text { CPL cloud } \\
\text { middle }\end{array}$ \\
\hline \multirow{2}{*}{ First } & Median error $(\mathrm{km})$ & 0.58 & 0.42 & 0.74 & 0.54 & 0.61 & 0.45 \\
& Mean error $(\mathrm{km})$ & 1.05 & 0.86 & 1.69 & 1.41 & 1.21 & 0.98 \\
& Np & 114515 & 114515 & 110221 & 110221 & 119683 & 119683 \\
& SD & 1.86 & 1.73 & 2.67 & 2.57 & 2.12 & 2.01 \\
& Corr. coeff. & 0.87 & 0.88 & 0.81 & 0.81 & 0.87 & 0.87 \\
\hline \multirow{2}{*}{ Second } & Median error $(\mathrm{km})$ & 1.26 & 1.19 & 1.69 & 1.52 & 1.30 & 1.18 \\
& Mean error $(\mathrm{km})$ & 1.92 & 1.80 & 2.60 & 2.36 & 2.28 & 2.09 \\
& Np & 48883 & 48883 & 51812 & 51812 & 61961 & 61961 \\
& SD & 2.79 & 2.67 & 3.29 & 3.19 & 3.25 & 3.14 \\
& Corr. coeff. & 0.71 & 0.72 & 0.66 & 0.66 & 0.69 & 0.69 \\
\hline \multirow{2}{*}{ Third } & Median error $(\mathrm{km})$ & 2.03 & 1.98 & 2.50 & 2.35 & 2.10 & 1.99 \\
& Mean error $(\mathrm{km})$ & 2.67 & 2.55 & 3.25 & 3.02 & 2.92 & 2.72 \\
& Np & 28493 & 28493 & 32766 & 32766 & 37577 & 37577 \\
& SD & 3.58 & 3.45 & 3.77 & 3.67 & 3.70 & 3.56 \\
& Corr. coeff. & 0.58 & 0.59 & 0.55 & 0.56 & 0.59 & 0.59 \\
\hline
\end{tabular}

\subsection{Error versus CTH}

As apparent from Figs. 4-6, the accuracy of the retrieved CTHs depends on the CTH itself. This section examines how the retrieval error changes with cloud height. Figure 10a and b show the vertical distribution of mean and absolute differences, respectively, for each band's first, second and third peaks against $1 \mathrm{~km}$ binned CPL heights. Figure 10c shows the number of points in each bin.

Figure 10a shows that the RSP consistently overestimates the height of low-lying clouds and underestimates the height of high clouds. Cloud top heights from about 14 to $17 \mathrm{~km}$ are underestimated in all cases. Qualitatively, the $1880 \mathrm{~nm}$ band largely overestimates the heights of clouds lower than $4 \mathrm{~km}$, which is expected considering the reduced sensitivity of the
1880 band for the lower atmosphere. Figure 10b shows that low-lying clouds are well retrieved by the $670 \mathrm{~nm}$ and dual band ranging from $\sim 1$ to $5 \mathrm{~km}$ for all layers. All bands have good ability to resolve CTH at mid-range altitudes between 5 and $9 \mathrm{~km}$. For CTH higher than $9 \mathrm{~km}$, the performance of each band generally decreases with increasing height in the atmosphere, with the $1880 \mathrm{~nm}$ band being the most accurate, followed by the dual band. Qualitatively, the $1880 \mathrm{~nm}$ band seems well suited to estimate CTH's from 4 to $17 \mathrm{~km}$ and the $670 \mathrm{~nm}$ band seems best suited to estimate CTH's from 1 to $13 \mathrm{~km}$. The dual band is accurate over a broader range $(1-16 \mathrm{~km})$ than either individual band, although it underperforms when compared to the $1880 \mathrm{~nm}$ band for the highest clouds. 
(a)

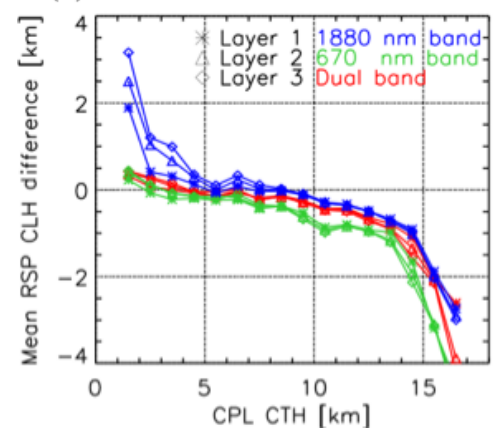

(b)

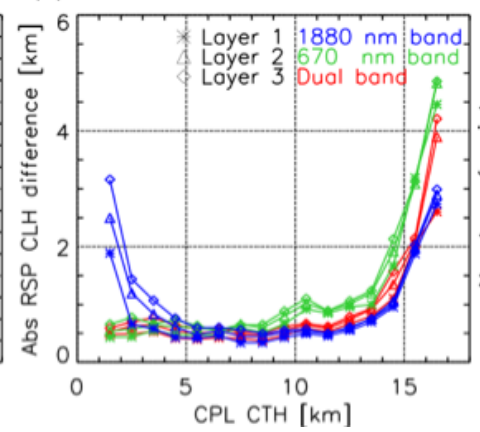

(c)

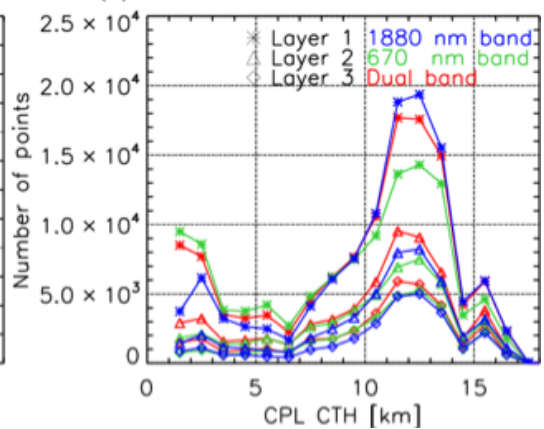

Figure 10. RSP mean error (a), absolute error (b) and number of clouds (c) versus CPL CTH.

\subsection{Optimized performance example}

Using the previous analyses, filters are implemented that use the strengths identified for each band. In Sect. 4.4, it was determined that in order to maximize the number of layer height retrievals, no minimum correlation threshold is used for the primary peak. Based on results shown in Fig. 7, for the second layer height, minimum correlation values of $0.3,0.4$ and 0.2 are chosen for the $1880 \mathrm{~nm}, 670 \mathrm{~nm}$ and dual band, respectively. For third-layer detection, minimum correlation of $0.5,0.7$ and 0.5 were chosen for the $1880 \mathrm{~nm}, 670 \mathrm{~nm}$ and dual band, respectively. This results in maximum errors of about $3 \mathrm{~km}$ for second and third layers for all bands. Based on results in Sect. 4.5, no minimum threshold on COT is implemented. According to findings shown in Sect. 4.6, the RSP CTH value is compared to CPL's cloud middle for all bands. In cases where no cloud bottom is determined by CPL, the comparison is done to CPL cloud top. From Sect. 4.7, we restrict comparisons for the $1880 \mathrm{~nm}, 670 \mathrm{~nm}$ and dual bands to $4-17,1-13$ and $1-16 \mathrm{~km}$, respectively. Table 4 summarizes the variables used for the $1880 \mathrm{~nm}, 670 \mathrm{~nm}$ and dual bands.

Using these values to filter layer detection, the median error, mean error, number of points, standard deviation and correlation coefficient were calculated for each band over the eight flights used in this comparison and are summarized in Table 5.

Results for each of the bands show a better agreement with the CPL observed heights than the initial analysis shown in Table 1. In Table 5 it can be seen that the $1880 \mathrm{~nm}$ band has the lowest errors of $0.43,1.35$ and 1.96 for the first, second and third layers, respectively. Overall, the errors associated with the $1880 \mathrm{~nm}$ and dual band are similar, while the $670 \mathrm{~nm}$ band yields somewhat larger errors for each layer. Compared to values listed in Table 1, the primary layer retrieval shows the largest improvement with CTH biases that are reduced by $150-190 \mathrm{~m}(26 \%)$ for each band. For the second and third layers for each band improvements are mainly apparent in the mean errors and standard deviation. In most cases, the primary and secondary layers retained nearly the same number of data points, while the third layer saw a signifi-
Table 4. Filters used for the optimal performance example.

\begin{tabular}{llll}
\hline & $1880 \mathrm{~nm}$ & $670 \mathrm{~nm}$ & Dual \\
\hline Cloud top or middle & Middle & Middle & Middle \\
Minimum COT & 0.0 & 0.0 & 0.0 \\
Minimum cloud height & $4.0 \mathrm{~km}$ & $1.0 \mathrm{~km}$ & $1.0 \mathrm{~km}$ \\
Maximum cloud height & $17.0 \mathrm{~km}$ & $13.0 \mathrm{~km}$ & $16.0 \mathrm{~km}$ \\
First peak minimum correlation & 0.00 & 0.00 & 0.00 \\
Second peak minimum correlation & 0.30 & 0.40 & 0.20 \\
Third peak minimum correlation & 0.50 & 0.70 & 0.50 \\
\hline
\end{tabular}

cant reduction in points used in each band due to the higher minimum correlation threshold. The correlation coefficients were either equal to the initial retrieval or reduced. Comparing these results to other studies, MISR has been found to have an accuracy in detecting a single-layer CTH with a standard deviation of about $1 \mathrm{~km}$ when compared to MODIS and ground-based retrievals (Naud et al., 2007; Marchand et al., 2010). Naud et al. (2007) found the difference in CTH reduces to $0.35 \mathrm{~km}$ when only low-lying liquid clouds are considered. Mixed-phase clouds were found to have differences of $0.4 \mathrm{~km}$ when compared to ground-based measurements above $5 \mathrm{~km}$ and $0.5 \mathrm{~km}$ when below $5 \mathrm{~km}$. MISR- and MODIS-detected opaque ice clouds were found to have a difference of $0.3 \mathrm{~km}$ and cirrus clouds $1.2 \mathrm{~km}$ (Naud et al., 2007). Here, we show a high number of comparisons and observe similar results for the $1880 \mathrm{~nm}$ and dual band configurations and a lower accuracy for the $670 \mathrm{~nm}$ band.

Figure 11 shows the $1880 \mathrm{~nm}$ band comparison of the first, second and third layers with CPL. For the primary peak (top left), a strong correlation can be seen. However, even with the improved filtering, some of the cases where RSP-retrieved cloud top height is higher than the CPL heights remain. The error distribution (left bottom) shows a narrow, symmetric peak that is closer to having a zero bias than seen in Fig. 4. The FWHM of the distribution is about $1.6 \mathrm{~km}$, which is an improvement from the results in Fig. $4(1.8 \mathrm{~km})$. The second and third peak comparisons remain similar to results shown in Fig. 4. Similarly, Figs. 12 and 13 show that comparisons 
(a)
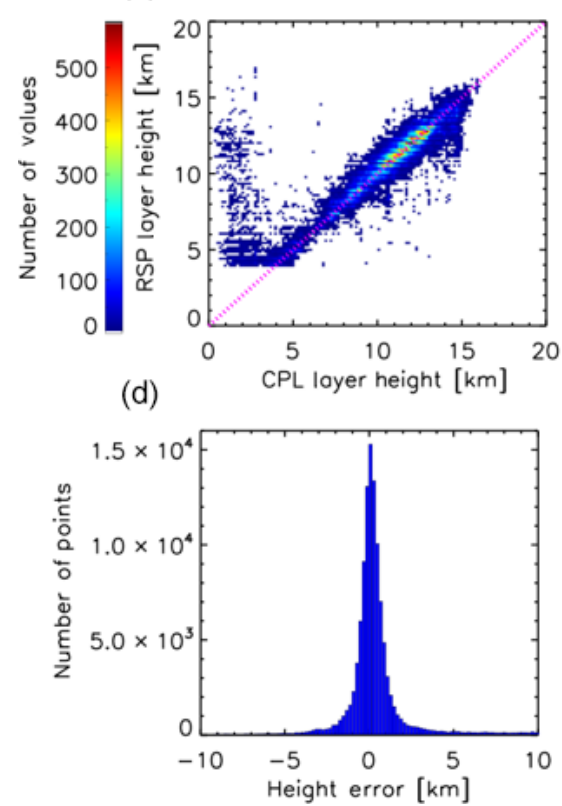

(b)

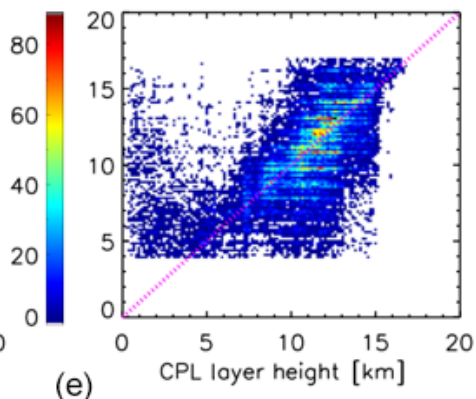

(e)

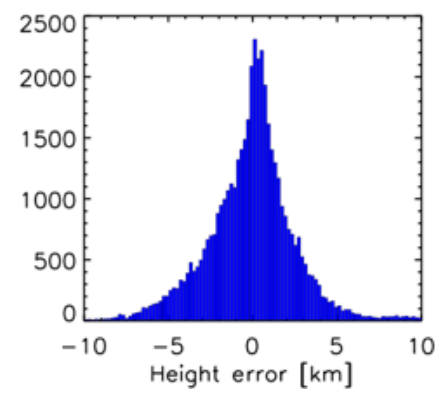

(c)

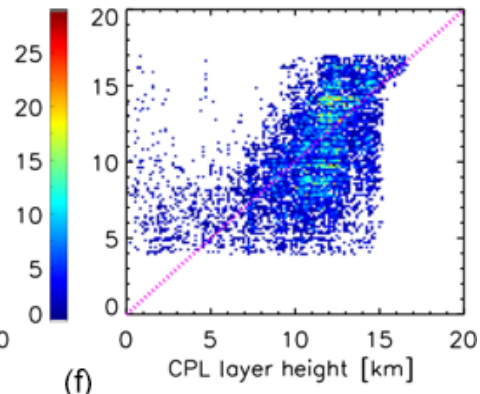

(f)

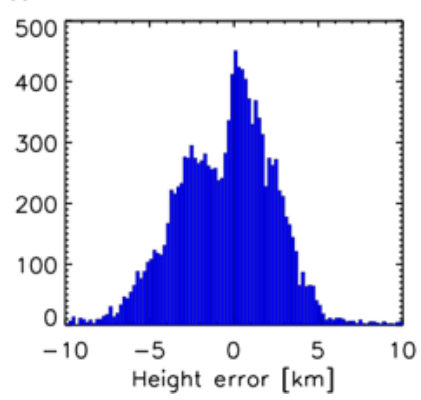

Figure 11. Comparison of CTH retrieved using the RSP $1880 \mathrm{~nm}$ band and CPL for the primary peak (top left), second peak (top middle) and third peak (top right) with their associated error distributions immediately below each scatterplot. Here, filters detailed in Table 4 are applied.

(a)

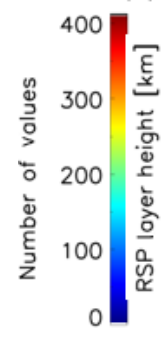

(d)

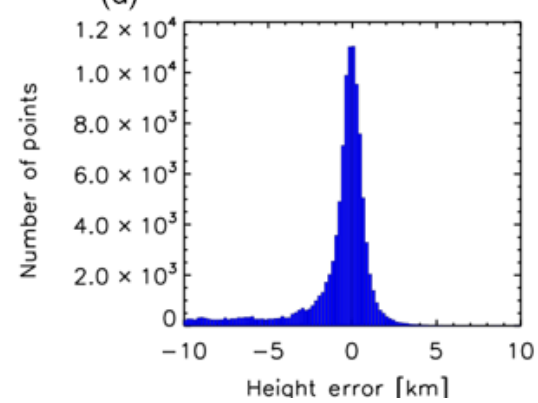

(b)

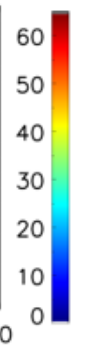

(e)

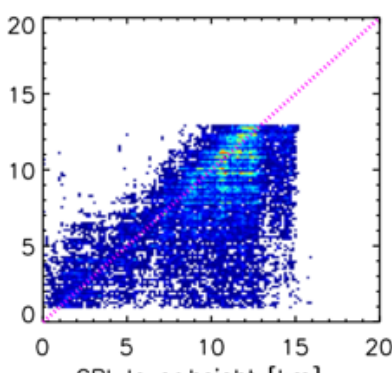

(e)

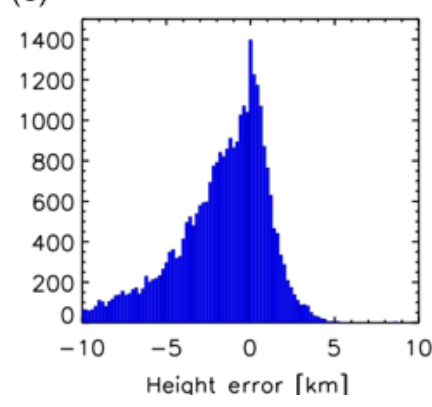

(c)
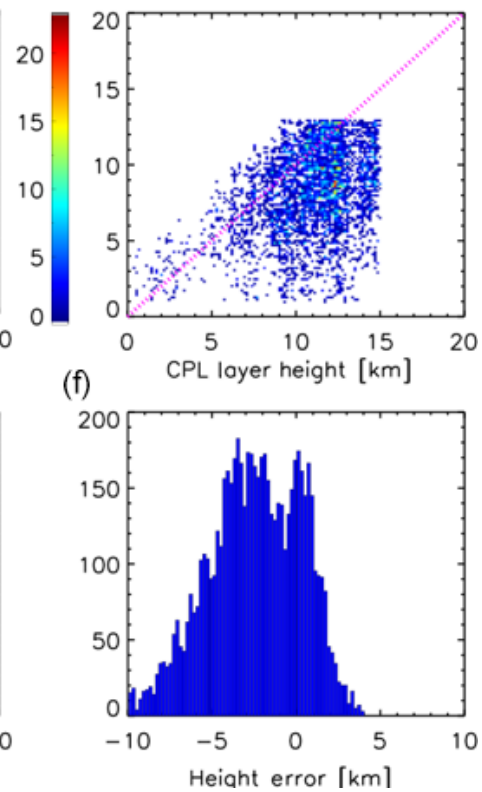

Figure 12. Same as Fig. 11 but for the $670 \mathrm{~nm}$ band results.

of the results from 670 and dual band retrievals with CPL are less biased than results shown in Figs. 5 and 6, but the tails of the distributions remain.

Table 6 shows the average cloud heights over all eight flights obtained using each band and CPL, along with the mean and median cloud layer separation and number of points used in each case. It can be seen that the statistics largely agree with the CPL, especially for the dual band configuration. 
(a)

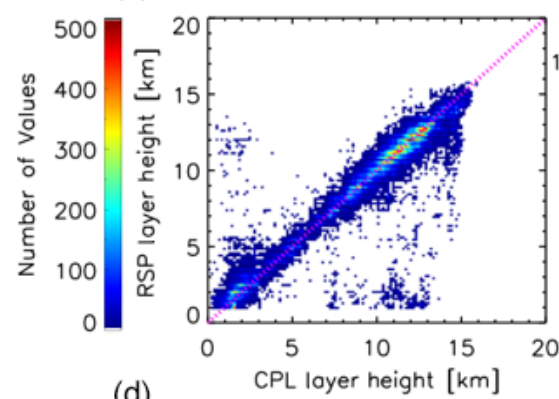

(d)

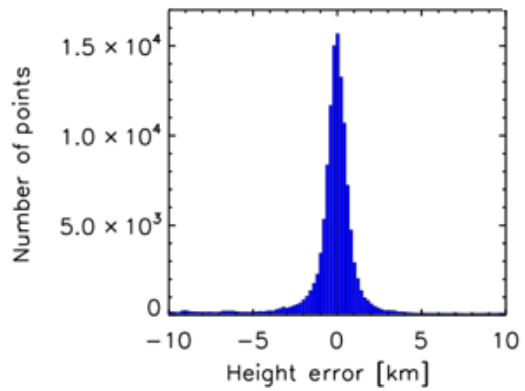

(b)

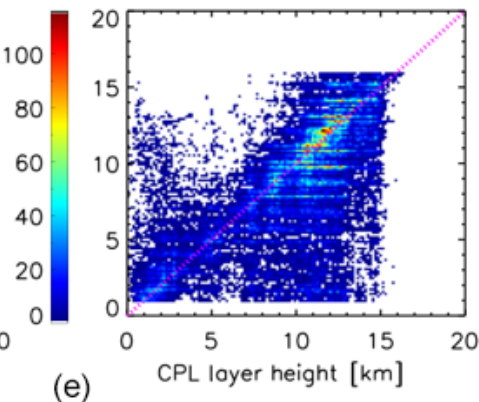

(e)

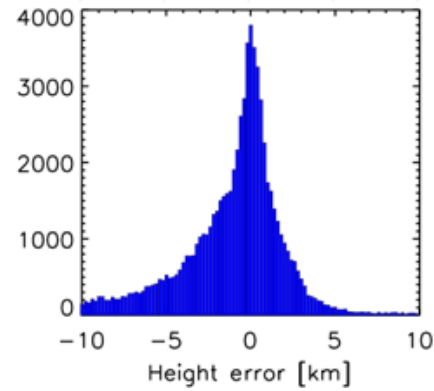

(c)

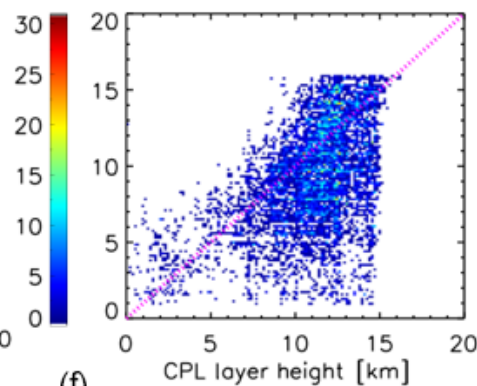

(f)

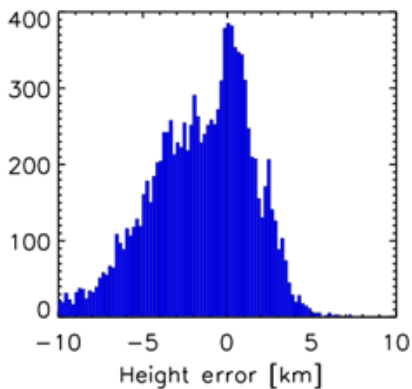

Figure 13. Same as Fig. 11 but for the dual band results.

Table 5. Summary of comparison with filters applied.

\begin{tabular}{llrrr}
\hline & & $\begin{array}{r}1880 \mathrm{~nm} \\
\text { band }\end{array}$ & $\begin{array}{r}670 \mathrm{~nm} \\
\text { band }\end{array}$ & $\begin{array}{r}\text { Dual } \\
\text { band }\end{array}$ \\
\hline First & Median error $(\mathrm{km})$ & 0.43 & 0.55 & 0.45 \\
& Mean error $(\mathrm{km})$ & 0.98 & 1.45 & 0.98 \\
& $\mathrm{~Np}$ & 109369 & 105783 & 121372 \\
& SD & 2.03 & 2.59 & 2.02 \\
& Corr. coeff. & 0.78 & 0.79 & 0.87 \\
\hline Second & Median error $(\mathrm{km})$ & 1.35 & 1.64 & 1.42 \\
& Mean error $(\mathrm{km})$ & 1.88 & 2.43 & 2.30 \\
& Np & 44851 & 30,257 & 67863 \\
& SD & 2.63 & 2.91 & 3.23 \\
& Corr. coeff. & 0.59 & 0.59 & 0.63 \\
\hline Third & Median error $(\mathrm{km})$ & 1.96 & 2.58 & 2.12 \\
& Mean error $(\mathrm{km})$ & 2.29 & 3.05 & 2.68 \\
& Np & 12858 & 6254 & 11247 \\
& SD & 2.90 & 2.87 & 3.13 \\
& Corr. coeff. & 0.51 & 0.36 & 0.46 \\
\hline
\end{tabular}

\section{Conclusion}

We presented a method of retrieving CTH using a multiangular contrast approach that can be applied to every RSP footprint. The technique uses a cross-correlation calculation between multiple viewing angles corresponding to cloud layers placed at specific altitudes. Local peaks in the calculated correlation profile as a function of height indicate the location of cloud layers. Multiple layers are identified by viewing
Table 6. Macro statistics.

\begin{tabular}{lrrrr}
\hline & $\begin{array}{r}1880 \mathrm{~nm} \\
\text { band }\end{array}$ & $\begin{array}{r}670 \mathrm{~nm} \\
\text { band }\end{array}$ & $\begin{array}{r}\text { Dual } \\
\text { band }\end{array}$ & CPL \\
\hline Mean layer height $(\mathrm{km})$ & 10.74 & 7.58 & 9.00 & 9.47 \\
Median separation $(\mathrm{km})$ & 2.10 & 1.90 & 2.50 & 2.67 \\
Mean separation $(\mathrm{km})$ & 2.47 & 2.54 & 3.38 & 4.35 \\
\hline
\end{tabular}

through optically thin layers. From this, we demonstrated the method's capability of retrieving multiple cloud layer heights within a single RSP footprint.

The cloud height retrieval accuracies associated with the magnitude of the correlation metric, optical thickness and cloud height were explored. It was shown that each band maintained accuracy when retrieving cloud layer heights with very low optical thicknesses. It was found that RSP cloud layer height retrievals more accurately correspond to the CPL-derived cloud middle rather than cloud top. The $1880 \mathrm{~nm}$ band works best at middle and high altitudes (4.0 to $17 \mathrm{~km}$ ), while the $670 \mathrm{~nm}$ band is best for low and middle altitudes $(1.0-13.0 \mathrm{~km})$. A dual band configuration that combines 670 and $1880 \mathrm{~nm}$ measurement was found to be capable of retrieving cloud layer heights at altitudes between 1.0 and $16.0 \mathrm{~km}$.

The approach works best at consistently identifying a primary layer height and was shown to be capable of retrieving secondary and even tertiary layer heights in certain cases. Improved accuracy is achieved by using customized filtering techniques for each band and layer with the most significant improvements occurring in the primary layer retrieval 
for each band. Compared to CPL, RSP is able to measure a primary layer's CTH with median error of about $0.5 \mathrm{~km}$. In instances where a second layer exists, the bands can measure the correct height with median errors ranging from 1.35 to $1.64 \mathrm{~km}$ and third layer heights from 1.96 to $2.58 \mathrm{~km}$. Our results suggest a general capability of multi-angular measurements for retrieving overlapping cloud layer heights.

Data availability. The underlying RSP data used in this study are publicly available at https://data.giss.nasa.gov/pub/rsp/SEAC4RS/ (Cairns, 2013). The CPL data used in this study are publicly available at https://cpl.gsfc.nasa.gov/ (McGill, 2013).

Competing interests. The authors declare that they have no conflict of interest.

Acknowledgements. Support for this work is provided by NASA grant no. NNX15AD44G (ROSES ACCDAM).

Edited by: A. Kokhanovsky

Reviewed by: three anonymous referees

\section{References}

Alexandrov, M. D., Cairns, B., Emde, C., Ackerman, A. S., and van Diedenhoven, B.: Accuracy assessments of cloud droplet size retrievals from polarized reflectance measurements by the research scanning polarimeter, Remote Sens. Environ., 125, 92$111,2012$.

Alexandrov, M. D., Cairns, B., Wasilewski, A. P., Ackerman, A. S., McGill, M. J., Yorks, J. E., Hlavka, D. L., Platnick, S. E., Arnold, G. T., van Diedenhoven, B., Chowdhary, J., Ottaviani, M., and Knobelspiesse, K. D.: Liquid water cloud properties during the Polarimeter Definition Experiment (PODEX), Remote Sens. Environ., 169, 20-36, 2015.

Alexandrov, M. D., Cairns, B., Van Diedenhoven, B., Ackerman, A. S., Wasilewski, A. P., McGill, M. J., Yorks, M. J. Hlavka, D. L., Platnick, S. E., and Arnold, G. T.: Polarized view of supercooled liquid water clouds, Remote Sens. Environ., 181, 96-110, 2016.

Boucher, O., Randall, D., Artaxo, P., Bretherton, C., Feingold, G., Forster, P., Kerminen, V.-M., Kondo, Y., Liao, H., Lohmann, U., Rasch, P., Satheesh, S. K., Sherwood, S., Stevens, B., and Zhang, X. Y.: Clouds and Aerosols, in: Climate Change 2013: The Physical Science Basis. Contribution of Working Group I to the Fifth Assessment Report of the Intergovernmental Panel on Climate Change, edited by: Stocker, T. F., Qin, D., Plattner, G.-K., Tignor, M., Allen, S. K., Boschung, J., Nauels, A., Xia, Y., Bex, V., and Midgley, P. M., Cambridge University Press, Cambridge, UK and New York, NY, USA, 2013.

Buriez, J. C., Vanbauce, C., Parol, F., Goloub, P., Herman, M., Bonnel, B., Fouquart, Y., Couvert, P., and Seze, G.: Cloud detection and derivation of cloud properties from POLDER, Int. J. Remote Sens., 18, 2785-2813, 1997.
Cairns, B.: RSP SEAC4RS Campaign Data, NASA Goddard Institute for Space Studies, available at: https://data.giss.nasa.gov/ pub/rsp/SEAC4RS/ (last access: 1 September 2016), 2013.

Cairns, B., Travis, L. D., and Russell, E. E.: The Research Scanning Polarimeter: Calibration and ground-based measurements, Proc. SPIE Int. Soc. Opt. Eng., 3754, 186-196, 1999.

Collins, W. D., Connant, W. C., and Ramanathan, V.: Earth radiation budget, clouds, and climate sensitivity, in: The Chemistry of the Atmosphere: its Impact on Global Change, edited by: Calvert, J. G., 207- 215, Blackwell Scientific Publishers, Oxford, UK, 1994.

Diner, D. J., Davies, R., Di Girolamo, L., Horvath, A., Moroney, C., Muller, J.-P., Paradise, S. R., Wenkert, D., and Zong, J.: MISR level 2 cloud detection and classification algorithm theoretical basis, Jet Propulsion Lab., JPL Tech. Doc. D-11399, Rev. D, Pasadena, CA, USA, 1999.

Fisher, D., Poulsen, C. A., Thomas, G. E., and Muller, J.-P.: Synergy of stereo cloud top height and ORAC optimal estimation cloud retrieval: evaluation and application to AATSR, Atmos. Meas. Tech., 9, 909-928, https://doi.org/10.5194/amt-9909-2016, 2016.

Lensky, I. M. and Rosenfeld, D.: The time-space exchangeability of satellite retrieved relations between cloud top temperature and particle effective radius, Atmos. Chem. Phys., 6, 2887-2894, https://doi.org/10.5194/acp-6-2887-2006, 2006.

Mace, G. G., Zhang, Q. Q., Vaughan, M., Marchand, R., Stephens, G., Trepte, C., and Winker, D.: A description of hydrometeor layer occurrence statistics derived from the first year of merged Cloudsat and CALIPSO data, J. Geophys. Res., 114, D00A26, https://doi.org/10.1029/2007JD009755, 2009.

Marchand, R., Ackerman, T., Smyth, M., and Rossow, W. B.: A review of cloud top height and optical depth histograms from MISR, ISCCP, and MODIS, J. Geophys. Res.-Atmos., 115, D16206, https://doi.org/10.1029/2009JD013422, 2010.

Marchand, R. T., Ackerman, T. P., and Moroney, C.: An assessment of Multiangle Imaging Spectroradiometer (MISR) stereo-derived cloud top heights and cloud top winds using ground-based radar, lidar, and microwave radiometers, J. Geophys. Res.-Atmos., 112, D06204, https://doi.org/10.1029/2006JD007091, 2007.

McGill, M.: CPL SEAC4RS Campaign Data, NASA Goddad Space Flight Center, available at: https://cpl.gsfc.nasa.gov/ (last access: 1 September 2016), 2013.

McGill, M., Hlavka, D., Hart, W., Scott, V. S., Spinhirne, J., and Schmid, B.: Cloud physics lidar: Instrument description and initial measurement results, Appl. Optics, 41, 3725-3734, 2002.

Menzel, W. P., Smith, W. L., and Stewart, T. R.: Improved cloud motion wind vector and altitude assignment using VAS, J. Clim. Appl. Meteorol., 22, 377-384, 1983.

Menzel, W. P., Frey, R. A., Zhang, H., Wylie, D. P., Moeller, C. C., Holz, R. E., Maddux, B., Baum, B. A., Strabala, K. I., and Gumley, L. E.: MODIS global cloud-top pressure and amount estimation: Algorithm description and results, J. Appl. Meteorol. Clim., 47, 1175-1198, 2008.

Meyer, K., Platnick, S., Arnold, G. T., Holz, R. E., Veglio, P., Yorks, J., and Wang, C.: Cirrus cloud optical and microphysical property retrievals from eMAS during $S A^{4} R S$ using bi-spectral reflectance measurements within the $1.88 \mu \mathrm{m}$ water vapor absorption band, Atmos. Meas. Tech., 9, 1743-1753, https://doi.org/10.5194/amt-9-1743-2016, 2016. 
Muller, J. P., Mandanayake, A., Moroney, C., Davies, R., Diner, D. J., and Paradise, S.: MISR stereoscopic image matchers: Techniques and results, IEEE T. Geosci. Remote, 40, 1547-1559, 2002.

Naud, C., Muller, J. P., and Clothiaux, E. E.: Comparison of cloud top heights derived from MISR stereo and MODIS $\mathrm{CO}_{2}$-slicing, Geophys. Res. Lett., 29, 42-1-42-4, https://doi.org/10.1029/2002GL015460, 2002.

Naud, C. M., Baum, B. A., Pavolonis, M., Heidinger, A., Frey, R., and Zhang, H.: Comparison of MISR and MODIS cloud-top heights in the presence of cloud overlap, Remote Sens. Environ., 107, 200-210, 2007.

Rosenfeld, D., Woodley, W. L., Lerner, A., Kelman, G., and Lindsey, D. T.: Satellite detection of severe convective storms by their retrieved vertical profiles of cloud particle effective radius and thermodynamic phase, J. Geophys. Res.-Atmos., 113, D04208, https://doi.org/10.1029/2007JD008600, 2008.

Toon, O. B., Maring, H., Dibb, J., Ferrare, R., Jacob, D. J., Jensen, E. J., Luo, Z. J., Mace, G. G., Pan, L. L., Pfister, L., Rosenlof, K. H., Redemann, J. S., Reid, J. S., Singh, H. B., Yokelson, R., Chen, G., Jucks, K. W., and Pszenny, A.: Planning, implementation, and scientific goals of the Studies of Emissions and Atmospheric Composition, Clouds and Climate Coupling by Regional Surveys (SEAC4RS) field mission, J. Geophys. Res.-Atmos., 121, 4967-5009, https://doi.org/10.1002/2015JD024297, 2016.

van Diedenhoven, B., Hasekamp, O. P., and Landgraf, J.: Retrieval of cloud parameters from satellite-based reflectance measurements in the ultraviolet and the oxygen A-band, J. Geophys. Res., 112, D15208, https://doi.org/10.1029/2006JD008155, 2007.

van Diedenhoven, B., Cairns, B., Fridlind, A. M., Ackerman, A. S., and Garrett, T. J.: Remote sensing of ice crystal asymmetry parameter using multi-directional polarization measurements Part 2: Application to the Research Scanning Polarimeter, Atmos. Chem. Phys., 13, 3185-3203, https://doi.org/10.5194/acp13-3185-2013, 2013. van Diedenhoven, B., Fridlind, A. M., Cairns, B., and Ackerman, A. S.: Variation of ice crystal size, shape, and asymmetry parameter in tops of tropical deep convective clouds, J. Geophys. Res.-Atmos., 119, 11809-11825, 2014.

van Diedenhoven, B., Fridlind, A. M., Cairns, B., Ackerman, A. S., and Yorks, J.: Vertical variation of ice particle size in convective cloud tops, Geophys. Res. Lett., 43, 4586-4593, https://doi.org/10.1002/2016GL068548, 2016.

Wang, J. and Rossow, W. B.: Effects of cloud vertical structure on atmospheric circulation in the GISS GCM, J. Climate, 11, 30103029, 1998.

Wang, J., Rossow, W. B., and Zhang, Y.: Cloud vertical structure and its variations from a 20-yr global rawinsonde dataset, J. Climate, 13, 3041-3056, 2000.

Wind, G., Platnick, S., King, M. D., Hubanks, P. A., Pavolonis, M. J., Heidinger, A. K., Yang, P., and Baum, B. A.: Multilayer cloud detection with the MODIS near-infrared water vapor absorption band, J. Appl. Meteorol. Clim., 49, 2315-2333, 2010.

Wu, M. L. C.: Remote sensing of cloud-top pressure using reflected solar radiation in the oxygen A-band, J. Clim. Appl. Meteorol., 24, 539-546, 1985.

Yorks, J. E., McGill, M., Hlavka, D., and Hart, W.: Statistics of Cloud Optical Properties from Airborne Lidar Measurements, J. Atmos. Ocean. Tech., 28, 869-883, https://doi.org/10.1175/2011JTECHA1507.1, 2011. 